\title{
Complex networks and simulation strategies: an application to olive fruit fly dispersion
}

\author{
Romanos Kalamatianos ${ }^{1}$, Markos Avlonitis ${ }^{2}$ \\ Department of Informatics \\ Ionian University \\ Corfu, Greece \\ c14kala@ionio.gr ${ }^{1}$, avlon@ionio.gr ${ }^{2}$
}

\author{
Spyros Stravoravdis \\ Build Environment Department \\ Greenwich University \\ London, UK \\ s.stravoravdis@gre.ac.uk
}

\begin{abstract}
In this work a study for the role of different environmental factors to the evolution of olive fruit fly, via an appropriate network of population traps is given. More explicitly, the olive fruit fly is a parasitic insect that infests olive groves in many countries. Through the use of a network of traps a simulation model was developed and used to simulate the dispersion of olive fruit fly inside a real olive grove for different environmental factors, such as different starting areas of olive fruit fly presence, different temperature sets as well as different drifting distances. Results showed that the level of infestation of the grove was not dependent on the limited areas the olive fruit fly emerged but on the drifting distance a fly could travel per day.
\end{abstract}

Keywords-trap network, simulation, modeling, olive fruit fly, dispersion

\section{INTRODUCTION}

Robust modeling of spatiotemporal environmental data has gain a lot of attention nowadays, because of their complex nature due to stochastic effects that emerge in real fields. To this end the use of a dense network of appropriate sensors or population traps is used in order to monitor and understand the underlying dynamic of environmental systems. Studies of such networks are focused either to the analyses of network data in order to attract knowledge and build analytical models or to the development of sophisticated simulation codes in order to explore dynamic properties of complex systems. In the following, an application of the aforementioned framework to the olive fruit fly is presented.

The parasitic insect pest Bactrocera Oleae commonly known as olive fruit fly, is a great menace of olive production in many olive oil producing countries. It causes significant damage in crop quality (aesthetic damage of fruit) as well as quantity (crop yield reduction) $[1,2]$.

During its biological cycle the olive fruit fly goes through four stages: egg, larva, pupa and adult. Olive fruits are the only growth habitat of the larva stage, thus adult female flies oviposit their eggs inside the olive fruits by stinging them. Once the larva emerges it feeds on the fruit which causes fruit damage and may result in a premature drop. The pupation stage can happen either inside the fruit or in the soil. Finally, when the adult flies emerge a new cycle of mating and oviposition begins [3].

The population dynamics of the olive fruit fly depends heavily upon environmental conditions. Temperature is an important, if not the primary, environmental factor that affects the development of the immature stages of the olive fruit fly [4, 5]. Many models have been designed and used to relate temperature with insect development. The most common model that is being used is the degree-day model. With this model the heat that an organism accumulates during the day, between lower and upper thresholds, is calculated in degreeday units. Also, the total amount of degree-days required for an organism to develop from one life stage to the other can be determined. The most common methods for calculating degreedays are the single sine curve and mean temperature methods [6]. Other methods used are the max-min, "saw-tooth" and double sine curve methods [7]

Another environmental factor that can affect the development of the olive fruit fly is Relative Humidity [8, 9]. Both Temperature and Humidity are affected by temporal and spatial variations of solar radiation, such as time of day and period of the year, sky conditions and the presence of shading. Furthermore, proximity to the sea, or to mountains and exposure to the wind among others, can also impact on environmental conditions, due to the creation of a microclimate. An olive grove field can all exist in the same microclimate, or depending on the size of it and the specific topographic conditions present, numerous micro-climates could exist. This paper adopts a simplified approach and assumes the same micro-climate for all of the olive grove site used.

In olive groves a network of traps is used to monitor the population of the olive fruit fly and data obtained by those traps can indicate the level of infestation. The main reason for the use of traps is because of the olive fruit fly's dispersion in the olive grove. Based on these data the following simulation model uses a network of traps to monitor the population of the olive fruit fly and can be used as a prediction tool. Other methods to monitor population outbreaks have been proposed $[10,11,12]$, where stochastic algorithms were used to predict population outbreaks of users watching a video. The simulation 
model used in this paper is based on work conducted by Voulgaris et al [13], where the robustness of the model was proved.

\section{Methodology}

\section{A. Simulation model}

Initially, the field where the evolution of the olive fruit fly's population would take place was constructed. The 2D grid that was constructed, simulated a real olive grove in St. George, Corfu, Greece with a total area of $9000 \mathrm{~m}$ x $7400 \mathrm{~m}$, was divided into $100 \mathrm{~m} \times 100 \mathrm{~m}$ trap cells. As a result the total grove is assumed that is covered by a grid network of $90 \times 74$ trap cells which were used to monitor the population of the olive fruit fly. Each monitoring cell was subsequently divided into 10 x 10 smaller cells, where each cell corresponded to a $10 \mathrm{~m} \times$ $10 \mathrm{~m}$ area. Fig. 1 displays the produced grid where black colored cells represent the olive grove area while white colored cells represent areas where there are no olive trees (settlements, roads, etc.). The overlaying grey cells represent the grid network of trap cells.

The population of the olive fruit fly was divided into two categories: the immobile, which corresponded to the egg, larva and pupal development stage, and the mobile, which corresponded to the perfect adult insect both sexually mature and immature, population.

The development of the immobile population, throughout the simulation, was achieved by using the degree-day model. For each insect that entered one of the three stages belonging in the immobile population the total amount of degree-day units, needed to evolve to the next stage is computed. The following function is used to compute the accumulated heat:

$$
\left(\mathrm{t}_{\mathrm{i}}-\mathrm{T}_{\mathrm{L}}\right) *\left(1-\left(1 / 1+\exp \left(-10 *\left(\mathrm{t}_{\mathrm{i}}-\mathrm{T}_{\mathrm{U}}\right)\right)\right)\right.
$$

where $t_{i}$ is the temperature of the $i$-th simulation step and $T_{L}$ and $\mathrm{T}_{\mathrm{U}}$ are the lower and upper developmental thresholds of the insect, respectively.

The adults of the mobile population in each simulation step

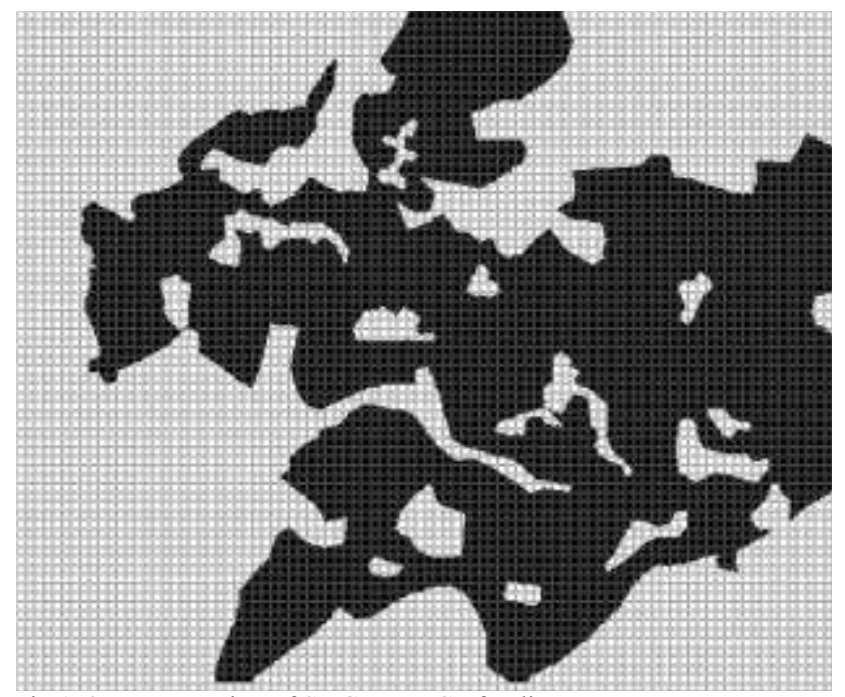

Fig 1. 2D construction of St. George, Corfu olive grove. either stay in the cell that they were positioned in the previous step or drift in another randomly selected cell, which represents an olive grove area, which is inside a randomly selected radius of cells. Adult dispersion inside the olive grove is temperature dependent and currently is affected by high temperatures. The maximum distance (D) that the olive fruit fly can travel per simulation step is calculated by the following equation:

$$
\mathrm{D}=\mathrm{d}_{\mathrm{i}} *\left(1-\left(1 / 1+\exp \left(-10 *\left(\mathrm{t}_{\mathrm{i}}-\mathrm{T}_{\mathrm{M}}\right)\right)\right.\right.
$$

where $d_{i}$ is the randomly computed maximum distance the olive fruit fly can travel in the $\mathrm{i}$-th simulation step, $\mathrm{t}_{\mathrm{i}}$ is the temperature of the $\mathrm{i}$-th simulation step and $\mathrm{T}_{\mathrm{M}}$ is the temperature motion threshold, which is set to $35^{\circ} \mathrm{C}$ [14] (as it is referenced in [15]). Fig. 2 displays the graph of (2), with $d_{i}$ set to $60 \mathrm{~m}$. All temperatures referred to, are ambient environmental temperatures.

The simulation starts with the emergence of the overwintered generation. For the first 40 steps of the simulation random numbers of adult flies, in the range of 100 and 250, are positioned randomly inside the $2 \mathrm{D}$ grid. In an attempt to simulate the ripeness of the olive fruit, when oviposition can commence, the adult flies of the overwintered generation can start to reproduce 30 steps after the simulation starts.

\section{B. Experiments}

In order to examine the dynamic behavior of the olive fruit fly in space and time we ran the simulation model for two scenarios. In the first scenario the overwintered generation could emerge only in $25 \%$ of the olive grove, while in the second scenario the emergence could occur only in $50 \%$ of the olive grove. We ran each simulation scenario under two different sets of temperatures (Fig. 3) and under three maximum distance constraints an adult fly can travel in each simulation step.

Temperatures were obtained from the Hellenic National Meteorological Service as they were documented by their meteorological station in Corfu, Greece. The distance between the station $\left(39^{\circ} 36^{\prime} 07^{\prime} ' \mathrm{~N}, 1^{\circ} 54^{\prime} 42^{\prime}{ }^{\prime} \mathrm{E}\right)$ and the olive grove site $\left(39^{\circ} 42^{\prime} 51.3^{\prime} ' \mathrm{~N}, 1^{\circ} 41^{\prime} 39.1^{\prime \prime} \mathrm{E}\right)$ is $22.41 \mathrm{~km}$, which can account for some variation due to differences in micro-climate. As these were the only reliable and available data, they were used in the simulation model. For both sets, temperatures from the time period of $21^{\text {st }}$ of June to $31^{\text {st }}$ of December were used.

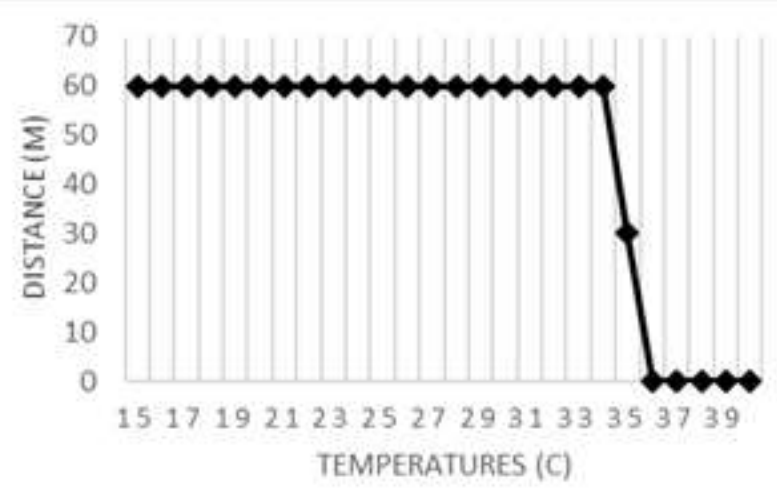

Fig. 2 Equation (2) graph, with $d_{i}$ set to $60 \mathrm{~m}$ and $\mathrm{T}_{\mathrm{M}}$ set to $35^{\circ} \mathrm{C}$. 


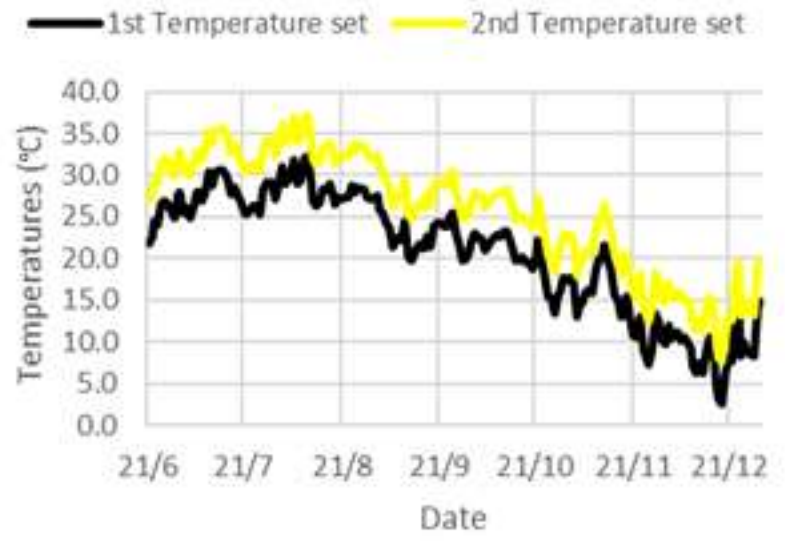

Fig. 3 Temperature sets.

The first set of temperatures were the mean daily temperatures of the year 2001 and the second set was the first temperature set increased by $5{ }^{\circ} \mathrm{C}$ uniformly throughout all time steps. This was done, so that a simplified version of a significantly warmer scenario can be tested. This could be in line with a future climate change scenario that takes into account of global warming, or a warmer climate in another location.

The average distance an olive fruit fly can travel when host availability is low is $400 \mathrm{~m}$. On the other hand, when host availability is over $30 \%$, average travel distance is shorter, about $180 \mathrm{~m}$. These findings were obtained from measurements done in Corfu, Greece [16] (referenced in [13]). Three distinct maximum drifting constrains were placed on the adult flies which indicated host availability in the olive grove. For each scenario and for each temperature set, simulation runs were conducted where the olive fruit fly could travel up to a $10 \mathrm{~m}$ (host availability is high) or $60 \mathrm{~m}$ or $150 \mathrm{~m}$ (host availability is low) radius, in each simulation step.

\section{RESULTS}

Fig. 4 displays the results of the simulation runs for the first scenario, where the overwintered generation could only emerge in $25 \%$ of the total olive grove. For each distance constrain it displays the dispersion of the olive fruit fly for the two temperature sets when the population size of the overwintered
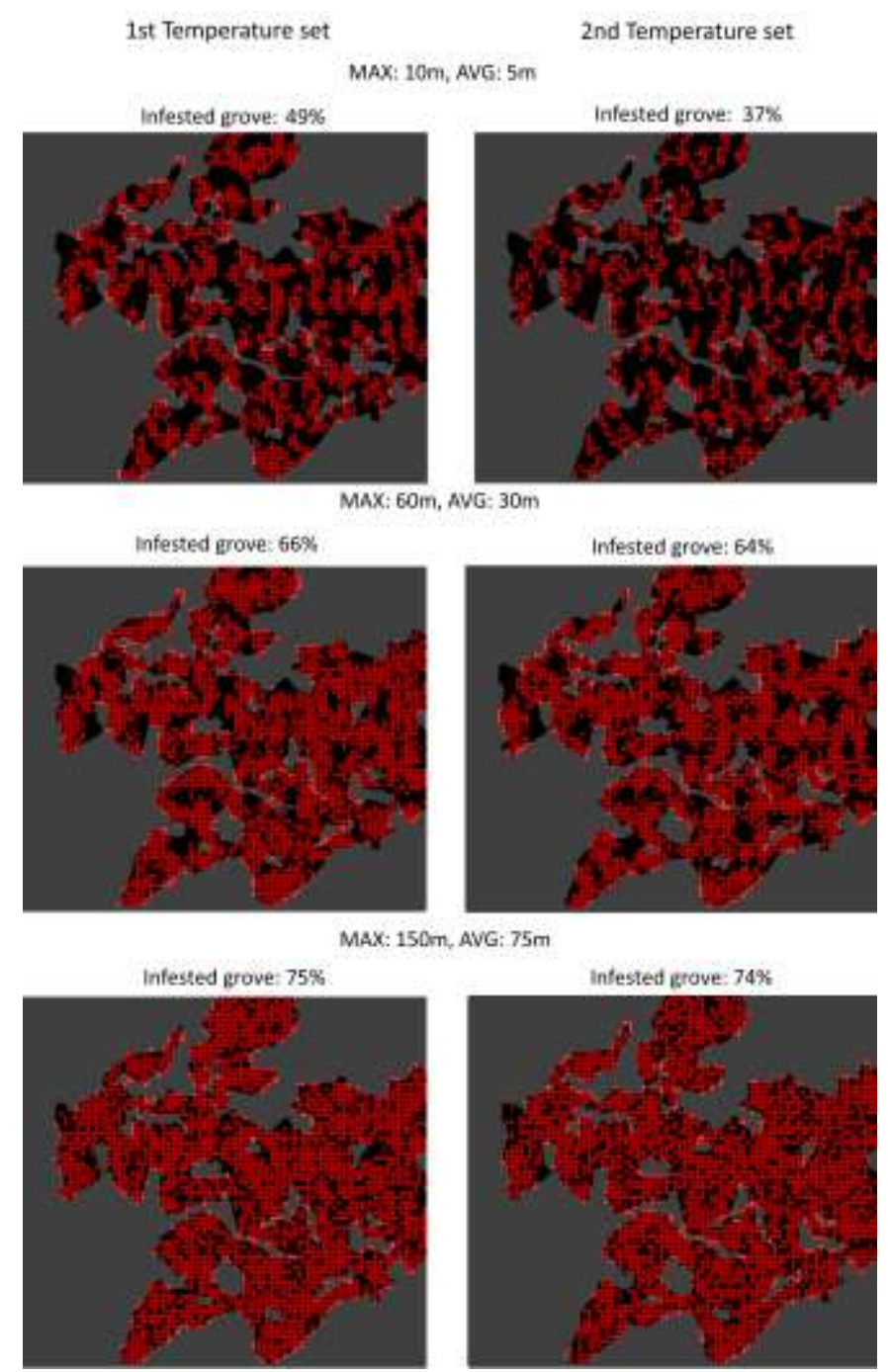

AVG: $75 \mathrm{~m}$ Intested grove: $74 \%$

Fig. 4 Olive fruit fly dispersion for first scenario under two temperature sets and drifting distance constraints. Red colored cells indicate infestation, black colored cells indicate no olive fruit fly presence. 
generation reaches its peak. Trap cells with red color indicate that the area is infested, while black colored cells indicate no olive fruit fly presence.

When the olive fruit fly can travel only small distances, like in the $10 \mathrm{~m}$ radius constrain, many cells (black cells) show no presence of the olive fruit fly. For the first temperature set about half of the olive grove is infested, while for the second temperature set the infestation level is significantly lower about $37 \%$. For larger distances, $60 \mathrm{~m}$ and $150 \mathrm{~m}$ constrain cases, infestation levels have increased to $65 \%$ and $74.5 \%$, on average, respectively.

The same behavior can be observed in Fig. 5, where the results of the simulation runs for the second scenario are displayed. In this scenario the overwintered generation could emerge only in $50 \%$ of the olive grove.

Again, in the $10 \mathrm{~m}$ radius constrain for the first temperature set $58 \%$ of the olive grove is infested. On the other hand, for the second temperature set the infestation level has decreased by $8 \%$. If we observe the results for the $60 \mathrm{~m}$ radius constrain the

1st Temperature set

\section{2nd Temperature set}

MAX: 10m, AVG: $5 m$
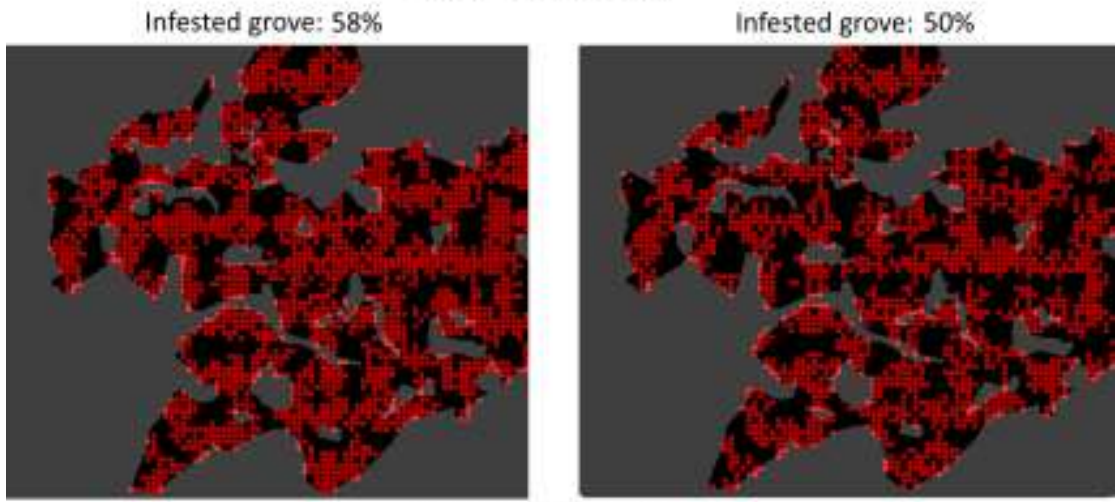

MAX: 60m, AVG: 30m
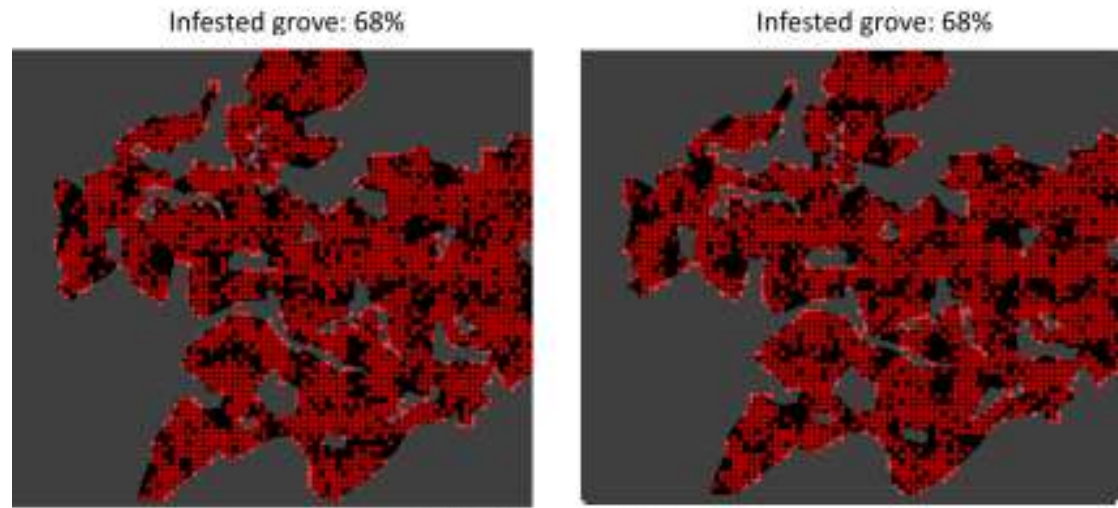

MAX: 150m, AVG: $75 \mathrm{~m}$

Infested grove: $75 \%$

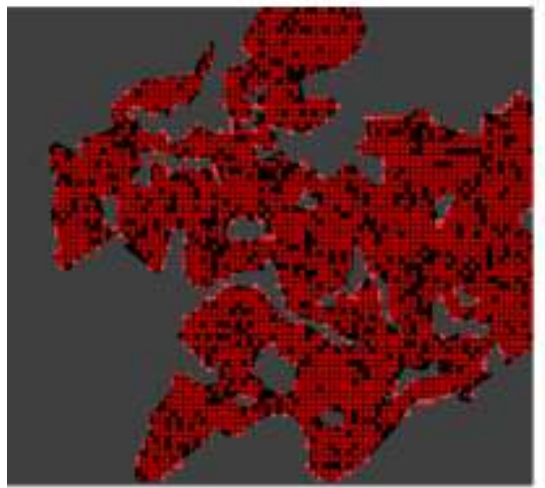

Infested grove: $74 \%$

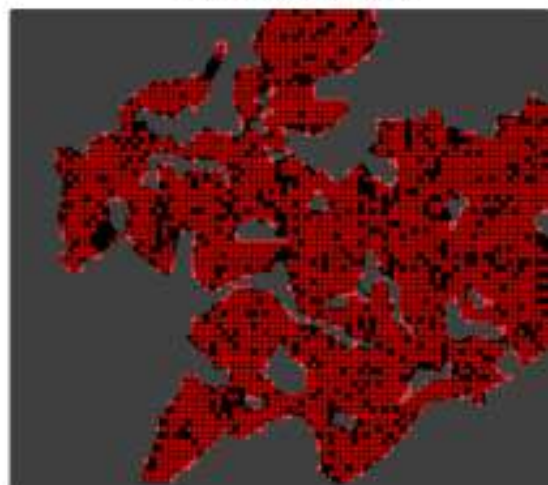

Fig. 5 Olive fruit fly dispersion for second scenario under two temperature sets and drifting distance constraints. Red colored cells indicate infestation, black colored cells indicate no olive fruit fly presence 
number for both temperature sets $68 \%$ of the olive grove has been infested. Finally in the $150 \mathrm{~m}$ radius constrain the olive fruit fly has infested three quarters of the olive grove.

When compared with the simulation runs in Fig. 4, one can observe that for the $10 \mathrm{~m}$ and $60 \mathrm{~m}$ distance constrains and both temperature sets, the level of infestation is greater. On the contrary, for the $150 \mathrm{~m}$ distance constrain infestation levels are the same. This difference in infestation can be attributed to the starting points of infestation. Specifically in the first scenario up to $25 \%$ of the grove could be infested while in the second scenario up to $50 \%$ of the grove could be infested and through drifting the olive fruit fly can more easily infest the rest of the grove.

Fig. 6 displays the olive fruit fly's population growth over time for both temperature sets. A total of four generations emerged including the overwintered generation for the first temperature set, while for the second temperature set three generations emerged. The first generation for the second temperature set has a quite large time gap from the overwintered generation, which is a result of the higher temperatures the olive fruit fly had to develop under.

\section{DISCUSSION}

Simulation runs were conducted for two different scenarios under two temperature sets and with different maximum drifting distance constrains on the mobile population of the olive fruit fly.

It was shown that no matter the number of starting areas the olive fruit fly emerges, even when the maximum travelling distance was $10 \mathrm{~m}$ per day, a considerable percentage of the olive grove was infested although there are large areas that had no presence of the insect. However when the maximum drifting distance increased, $60 \mathrm{~m}$ and $150 \mathrm{~m}$ cases, the limited areas the overwintered adult insects emerged didn't seem to hinder the infestation of a considerable percentage of the olive grove.

Finally, for simulation runs where the temperatures were higher, which was the case with the second temperature set, the dispersion of the olive fruit fly inside the olive grove didn't seem to be affected when the olive fruit fly could travel greater distances $(60 \mathrm{~m}$ and $150 \mathrm{~m})$, because host availability was low. On the other hand, when host availability was high and thus olive fruit fly traveled a smaller distance $(10 \mathrm{~m})$, the olive fruit fly didn't dispersed much inside the olive grove.

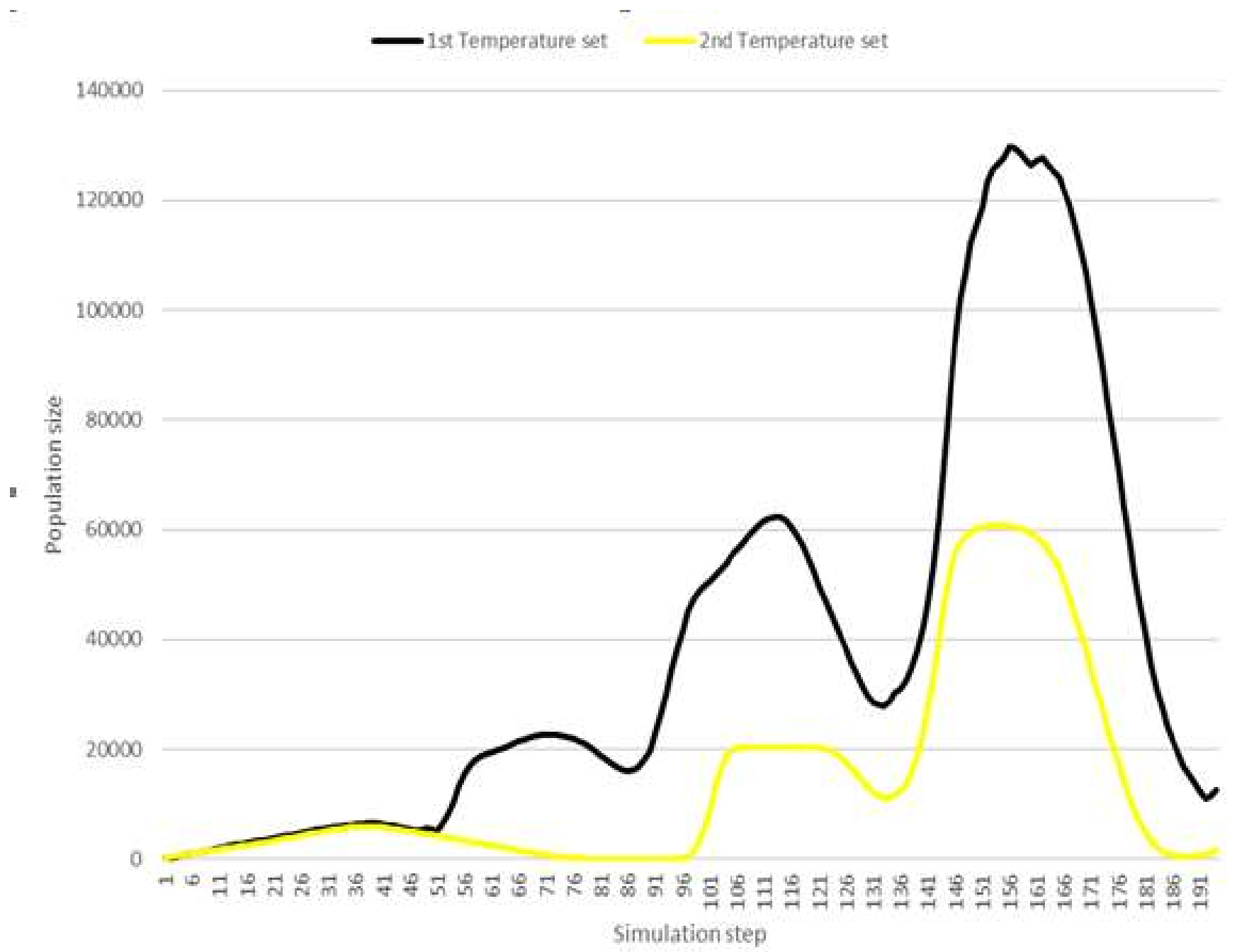

Fig. 6 Olive fruit fly's population dynamics under two temperature sets. 
We conclude that the number of infested areas is a function of host availability and temperature.

Through a network of traps our simulation model can monitor the population size of the olive fruit fly during time as well as the dispersion of the flies in space. Our model could be used as a prediction and risk assessment tool of olive fruit fly's outbreaks.

\section{FUTURE WORK}

Temperature and Relative Humidity data are being collected on another olive grove site, so that temporal and spatial variations on environmental conditions can be captured and thus micro-climatic conditions established. The data will then be used to further test, extend, refine and validate the developed simulation model.

\section{ACKNOWLEDGMENT}

Financial support of the European Union and of National Funds of Greece and Albania under the IPA Cross-Border PROGRAMME "Greece - Albania 2007 -2013", project title "Enhancing Olive Oil Production with the use of Innovative ICT" with the acronym "e-Olive", is gratefully acknowledged.

\section{REFERENCES}

[1] R. Rice, Bionomics of the Olive Fruit Fly Bactrocera (Dacus) olea, UC Plant Protection, 2000, 10(3).

[2] P. Neuenschwander and S. Michelakis, Infestation of Dacus oleae (Gmel.)(Diptera, Tephritidae) at harvest time and its influence on yield and quality of olive oil in Crete, Journal of Applied Entomology, 1978, $86: 420-433$

[3] P. Vossen, L. Varela and A. Devarenne, Olive fruit fly, University of California Cooperative Extension - Sonoma County, September 2006.

[4] BS. Fletcher, Temperature-development rate relationships of the immature stages and adults of tephritid fruit flies, World Crop Pests: Fruit Flies-Their Biology, Natural Enemies and Control, ed. AS Robinson, G Hooper, 1989, 3A:273-89. Amsterdam: Elsevier.
[5] H. Genc and JL. Nation, Survival and development of Bactrocera oleae Gmelin (Diptera: Tephritidae) immature stages at four temperatures in the laboratory, Afr. J. Biotechnol, 2008, 7:2495-500.

[6] P. W. Brown, Heat units, Extension Report 8915, University of Arizona College of Agriculture, 1989, 12pp

[7] Wilson, L. T. and W. W. Barnett, Degree-Days: an aid in crop and pest management. California Agricultur, 1983, 37:4-7

[8] V.Y. Yokoyama, R.A. Rendon and J Sivinski, Biological Control of Olive Fruit Fly (Diptera: Tephritidae) by Reseases of Psyttalia cf. concolor (Hymenoptera: Braconidae) in California, Parasitoid Longevity in Presence of the Host, and Host Status of Walnut Husk Fly. Proceedings of the $7^{\text {th }}$ International Symposium on Fruit Flies of Economic Importance. 10-15 September 2006, Salvador, Brazil pp.157164

[9] G.D. Broufas, M.L. Pappas and D.S. Koveos, Effect of Relative Humidity on Longevity, Ovarian Maturation, and Egg Production in the Olive Fruit Fly (Diptera: Tephritidae), Anns of th Entomological Society of America 2009, 102(1): pages 70-75, http://dx.doi.org/10.1603/008.102.0107

[10] Avlonitis, M., Karydis, I., Chorianopoulos, K., Sioutas, S., 2013. Treating Collective Intelligence in Online Media. CRC Press / Taylor \& Francis. chapter Semantic Multimedia Analysis and Processing.

[11] Karydis, I., Avlonitis, M., Chorianopoulos, K., Sioutas, S., 2013. Identifying important segments in videos: A collective intelligence approach. International Journal on Artificial Intelligence Tools.

[12] Karydis, I., Avlonitis, M., Sioutas, S., 2012. Collective intelligence in video user's activity, in: Artificial Intelligence Applications and Innovations (2), pp. 490-499.

[13] S. Voulgaris, M. Stefanidakis, A. Floros and M. Avlonitis, Stochastic modeling and simulation of Olive Fruit Fly outbreaks, Procedia Technology. 2013. Volume 8, Pages 580-586, ISSN 2212-0173, http://dx.doi.org/10.1016/j.protcy.2013.11.083.

[14] Avidov Z. 1954. Further investigations on the ecology of the olive fl y (Dacus oleae, Gmel.) in Israel. Ktavim 4:39-50.

[15] Johnson M, Wang X, Nadel H, Opp S, Lynn-Patterson K, Stewart-Leslie J, Daane K. 2011. High temperature affects olive fruit fly populations in California's Central Valley. Calif Agr 65(1):29-33. DOI: 10.3733/ca.v065n01p29

[16] Fletcher BS, Kapatos E. 1981. Dispersal of the Olive Fly, Dacus Oleae, during the Summer Period on Corfu. Exp. \& appl. (29):1-8 